\title{
Justice: A Case of False-Positive HIV Employee
}

\section{Wais Mohammad Qarani ${ }^{*}$ and Sobia Idrees}

French Medical Institute for Children, Kabul, Afghanistan

*Corresponding author: Qarani WM, French Medical Institute for Children, Nursing Division, FMIC, Behind Kabul Medical University, Kart-e-Sakhi, Kabul, Afghanistan, Tel: 00923471221606; E-mail: wais.qarani@gmail.com

Received date: June 01, 2015; Accepted date: August 12, 2015; Published date: August 17, 2015

Copyright: $\odot 2015$ Qarani WM. This is an open-access article distributed under the terms of the Creative Commons Attribution License, which permits unrestricted use, distribution, and reproduction in any medium, provided the original author and source are credited.

\begin{abstract}
Human immunodeficiency virus (HIV) significantly attributes to social stigmatization, besides being a health concern. It is one of the major responsibilities of the health care providers to practice caution before labeling a person with such diagnosis, as sometimes it is predicted to be false-positive. No doubt, health care employees are not exempted from acquiring the disease. However, inaccurate decisions could cause abundant consequences on a person's personal and psychosocial wellbeing. Therefore, the higher management team of an entity has the prime responsibility to be fair with the employees and utilize the principle of justice in their actions. Indeed, moral responsibilities and ethical values play an important role in fairly decision-making in everyone's life. Afghan women suffer from various unhealthy cultural and traditional practices besides other social inequalities. For this, strategies to encourage women in labor market and avoid gender discrimination must be launched. Furthermore, attempts to maintain justice through designing specific policy and protocol to avoid errors within an organization must be prioritized.
\end{abstract}

Keywords HIV; Justice; Confidentiality; Termination; Social stigma; False positive

\section{Introduction}

Human immunodeficiency virus (HIV) is a viral infection that affects the immune system of an individual. According to World Health Organization report (2013), around 35.3 million people in 2012 were living with HIV where the prevalence was highest among males. It is estimated by United Nation programs for AIDS (UNAIDS) and Pakistan national AIDS control program that there are around 79,000 cases of HIV in Pakistan [1]. In Afghanistan although the registry for this fatal ailment may not be comprehensive, it is believed that around 5,000 people are living with HIV [2]. This number may not depict the actual figure, as millions of Afghans are immigrant in different countries and would have acquired the infection. To consider the above statistics, we cannot ignore a huge number of individuals to be directly or indirectly part of our workplace. HIV is a disease possessing the most stigmas in the community. The diagnosis of the disease sometimes could be false-positive, however in both the cases it causes social and ethical conflicts. To make an in-depth understanding of the ethical principles and rules pertaining to workforce with false-positive HIV, we would consider the below scenario as a theme for discussion.

\section{Scenario}

A 20-year-old female working as a laboratory technician was diagnosed as HIV positive in a tertiary care hospital in Kabul, Afghanistan. Consequently, she was terminated from her job based on the decision taken by the senior management of the hospital. One year later, she re-visited the hospital and claimed that she has checked her status in one of the neighboring country indicating HIV negative; while she has already broken her engagement and borne social stigmas. To reflect on the above situation, the principle of justice evokes discussions considering the ethical, social, and legal aspects of this scenario.

\section{Discussion and Analysis}

The first discourse which is evoked while conferring about HIVpositive individuals is that whether to disclose the status of the HIV patient or not? Labeling an individual as HIV-positive is a sensitive issue and holds the maximum social stigma than any other ailment. Breaking patient's confidentiality is dependent on whether the health status poses any risk to others or not.

In the above scenario, the employee was neither involved in invasive procedures, nor assigned in tasks pertaining to direct patient care. Despite the false-positive result, there is no justification for the disclosure of employee's confidentiality and her termination. Thus, the principle of justice with employee has been violated in this scenario.

The principle of justice is defined by Burkhardt and Nathaniel [3] as "the duty to treat all people fairly without regard to age, socioeconomic status, race, or gender", and in this case disease status. This notion guides an individual towards morally acceptable decisions and provides everyone an equal treatment. Considering the above scenario: was justice implied to aforementioned employee? Was the decision taken by the senior management fair and morally acceptable? I personally believe that it was not ethically a fair decision even if the employee would have been HIV true-positive.

In the real context, people who are labeled as HIV positive are socially excluded from the society and they are deprived from social interactions and rights. On the other hand, justice is an ethical principle which is highly valued and expected by the social norms. Indeed, every individual strives to be treated equally in accordance with social rights and fair decisions; a notion emphasized by the egalitarians. Furthermore, the international guidelines on human rights and HIV/AIDS, guide the states to facilitate people living with HIV/AIDS with all the privileges as for other individuals. The 
international guidelines, elaborate 12 right-based responses "in the area of law, administrative policy and practice" [4] to meet the mandate of human rights.

Justice is considered as a supreme moral virtue in Islam as declared that "God commands justice and fair dealing" [5]. It has also been highlighted by the Islamic rules that the Prophet Mohammad said that "An Arab has no superiority over a non-Arab nor a non-Arab has any superiority over an Arab; also a white has no superiority over black nor a black has any superiority over white except by piety and good deeds" [6]. This principle is generalized to cases of the similar nature that an individual should not be discriminated through any means such as health status. If we consider the mentioned case as truepositive, some may argue that presence of HIV-positive individual within the workplace pose risk to others. However, it is evident that transmission of HIV is medically established to be through certain body fluids and not through contact. Therefore, precautionary measures could minimize the risk. We acknowledge those healthcare jobs which involve invasive procedures are the only, which pose direct risk to others. Therefore, in such situations individuals could be assigned to the tasks that are non-invasive instead of terminating the staff. In the above scenario the decision has been taken regardless of integrating the principle of justice and fairness; a notion which is highly encouraged by the Prophet Mohammad that on the day of judgment the God will shelter the just leader under his shade [7].

The long run negative effect of HIV may include diminished productivity, thus leading to low organizational outcome. However, there is no doubt that the individual will function optimally during the initial stage of disease, and "as the disease progresses, alternative employment arrangements such as flexible working hours and jobsharing could be implemented" [8]. Furthermore, the quality of life of people living with HIV/AIDS in Taiwan was associated with factors such as; higher social support and reduced mood disturbances and distress [9].

Therefore, decision towards termination of such individual creates not only social concerns, but also economic consequences to the individual and her dependents. Furthermore, the stigma that is borne by the person labeled as HIV-positive will create vast psychosocial concerns to an individual leading to health related consequences. Therefore, it is significant to consider the international guidelines in regards to the human rights to avoid any catastrophic consequences to the quality of life of people living with HIV/AIDS.

Most importantly, specific to the above scenario, Afghan women have recently got the opportunity to be involved in the labor market. Therefore, it is important to employ women to the largest extent, as Afghan women already bear lots of other social and cultural disputes. This is despite the fact that the states are required to promote a supportive environment for the women under the international guidelines on HIV/AIDS and human rights [4].

In most of the developed countries HIV-positive individuals are protected by the law against all injustice and any other discrimination. If this scenario would have happened in any of the developed country, it would have massive legal consequences to the institution. However, in Afghanistan individuals neither know whom to approach, nor they are socially or culturally encouraged to do so. In a country, such Afghanistan majority of the public are unaware of their rights and institution's accountability. Although the aforementioned staff has borne lots of consequences including social stigma, loss of job, and breakage of engagement; she did not take the case to the court despite an evident error in diagnosis. But, we may reflect and estimate the monetary and nonmonetary cost of these consequences to the individual both in short and in long run. Therefore, our ethical decision making should be sensible and justifiable on the basis of moral and ethical values and universal rules and principles.

\section{Recommendations}

HIV is a sensitive issue and always has stigma with it; thus we must be cautious while making any diagnosis. There are incidents that the primary screening showed a positive result where the confirmatory test showed a negative result. The same incidents reported where two cases were reported as false-positive HIV in Pakistan after which they were confirmed as HIV negative [10,11]. Therefore, hospitals should design procedures for the confirmatory diagnosis of the HIV patients, particularly when employees are involved. Attempt to restore justice through developing specific policy pertaining to these sensitive issues must be prioritized. Particularly, a policy to protect the confidentiality right of the people living with HIV/AIDS in the workplace should be executed to avoid any consequences to the affected individual. Finally, endorsement of state law has to address the right of individuals within the society and also in their workplace is an important strategy to decrease stigmatization and other errors in health care industry.

\section{Conclusion}

Attitude of management authorities towards individuals labeled with HIV contributes to unfair treatment which has its unwanted consequences including psychological, social, and financial disputes to the individual. Discrimination at any level or on any base is prohibited by the Islamic rules and also by the social and ethical norms and is considered against human right. In fact, all need a safe workplace environment, which could be created through developing policies addressing precautionary measures necessary to avoid spread of such infections. Furthermore, ethical decisions should be based on confirmed evidence, and justice has to be acknowledged as a key direction for a fair decision.

\section{Acknowledgements}

Dr. Rozina Karmaliani, professor at School of Nursing and Midwifery, Aga Khan university, Karachi, Pakistan and Dr. Robyna Irshad Khan, assistant professor in anesthesiology department at Aga Khan University, Karachi, Pakistan are acknowledged for their support and feedback to improve and to complete this paper.

\section{References}

1. WHO (2013) HIV/AIDS: Pakistan.

2. Mehdi SZ (2013) The new Crisis in Afghanistan: HIV/AIDS Up by $38 \%$ in 2013. Afghan Zariza.

3. Burkhardt MA, Nathaniel AK (2008) Ethics and Issues in Contemporary Nursing. Delmar Cengage Learning, United States.

4. United Nations (2006) HIV/AIDS and Human Rights: International Guidelines. Office of the United Nations High Commissioner for Human Rights and the Joint United Nations Programme on HIV/AIDS. Geneva.

5. Quran, 16:90

6. Musnad Ahmad, 411/5

7. Sahih Muslim. Jami`at-Tirmidhi: Chapters 36 on Zuhd, Hadith 88.

8. Botes A, Otto M (2003) Ethical dilemmas related to the HIV-positive person in the workplace. Nursing Ethics 10: 281-294. 
Citation: Qarani WM, Idrees S (2015) Justice: A Case of False-Positive HIV Employee. J Clinic Res Bioeth 6: 233. doi: 10.4172/2155-9627.1000233

Page 3 of 3

9. Yang M, Chen Y, Kuo B, Wang K (2003) Quality of life and related factors for people living with HIV/AIDS in Northern Taiwan. Journal of Nursing Research 11: 217-225.
10. Ikram N, Ahamd S (2012) Case Report False Positive HIV Test in Low Prevalence Region. Pakistan J Ayub Med Coll Abbottabad 24: 116-117.

11. WHO (2013) HIV/AIDS: Afghanistan. 